\begin{tabular}{|l|l|l|l|l|l|}
\hline Revista Clío América & ISSN: 1909-941X & Vol. 10 & No. 20 & Julio - Diciembre de 2016 & 160 - 170 \\
\hline \multicolumn{6}{|c|}{ DOI: http://dx.doi.org/10.21676/23897848.1874 } \\
\hline
\end{tabular}

\title{
Antecedentes y orígenes de la Empresa Licorera de Santander (Colombia) 1785-1948
}

\author{
Background and origins of the Empresa Licorera de Santander (Colombia) 1785-1948
}

Resumen: El desconocimiento historiográfico nacional y regional sobre la historia de la Empresa Licorera de Santander (ELS) exigió un rastreo exhaustivo a los antecedentes históricos y sus orígenes en el siglo XX. El antecedente más remoto fue la Real Fábrica de Aguardiente del Socorro en el siglo XVIII, sus orígenes se remontan desde la aparición de la legislación de la lucha antialcohólica hasta su ratificación como empresa industrial y comercial a mitad de siglo XX.

Esta aproximación histórica comparó las dos experiencias industriales, siendo el éxito fiscal o monetario en la implementación del sistema de administración directa, el componente que iguala ambos casos, a pesar de su distancia temporal y el contexto. Por otro lado, esta investigación invita a nuevos estudios sobre la Empresa Licorera de Santander.

Palabras clave: Monopolio, Política Fiscal, Empresas públicas, Vino y bebidas espirituosas

JEL: D42, E62, L32, L66

Abstract: The national and regional historiographical ignorance about the history of the Empresa Licorera de Santander (ELS), demanded a thorough to the historical background and its origins in the twentieth century crawl. The earliest predecessor was the Real Fabrica de Aguardiente de Socorro in the eighteenth century and its origins date back from the appearance of the anti-alcohol legislation struggle until its ratification as industrial and commercial company mid- twentieth century.

This historical approach compared the two industrial, being the fiscal or monetary success in implementing the system of direct management, the component that matches both cases, despite their distance in time and context. On the other hand, this research invites further studies of the Empresa Licorera de Santander.

Keywords: Monopoly, Fiscal Policy, Public Enterprises, Wine and Spirits
Freddy Alexander Sierra-Garzón

Magister en Historia y Docente en la Licenciatura en Ciencias Sociales, Universidad

la Gran Colombia, Bogotá, Colombia.

Email: freddy.sierra@ugc.edu.co

Tipología: Artículo de Reflexión Fecha de Recibido: Mayo 10 de 2016 Fecha de Aceptación: Octubre 20 de 2016

Para citar este artículo:

Sierra, G. F. (2016) Antecedentes y orígenes de la empresa licorera de Santander (Colombia) 1785-1948. Clío América, 10(20), pp. 160 - 170 


\section{Introducción}

Bajo el título "Licorera de Santander pasa su último Trago" el periódico el Tiempo sentenciaba el fin de la Empresa Licorera de Santander por el decreto \#18 del 2000. Las causas fueron: la politiquería, la burocracia, la mala reformulación de sus productos y las multas que ocasionaron el descalabro financiero de lo que fue en algún momento una de las principales fabricas del país y su producto insignia Aguardiente Superior terminó siendo producido por la empresa de Cundinamarca (Value, 2000). Este artículo de prensa es una de las primeras referencias en la Internet acerca de la Empresa Licorera de Santander, pero ¿qué se conoce sobre los antecedentes y su origen?

La anterior pregunta parece ingenua, pero la realidad al interior de la historiografía local y nacional colombiana evidencia un total desconocimiento; para el siglo XVIII, los trabajos de Gilma Mora y Felipe González esbozan el contexto y características no sólo de las Reales fábricas, sino también del sistema de administración de la renta durante la Colonia. En el siglo XIX, tras la formación del Estado-Nación colombiano no hubo fábricas oficiales porque su sistema de administración fue de arriendo. De igual forma, para el territorio de Santander, sólo una tesis de Claudia Páez describe las características de la administración de la renta de aguardiente durante el periodo radical.

Con la legislación de la lucha antialcohólica entre 1923-1928 en el siglo XX, se retoma el sistema de administración directa y con ella la creación de fábricas oficiales de aguardiente y otros licores destilados. La historiografía nacional colombiana no ha prestado atención a las fábricas tanto en su aporte a la industrialización del país como a la economía nacional y a todas las relaciones que se tejen en términos políticos y sociales.

A manera de balance está "la historiografía económica colombiana del siglo XIX" de Rodríguez (1995) quien determinó cuatro grandes áreas: agroexportador, agraria, monetario y fiscal. Respecto a la última no aparecen trabajos centrados en el análisis de la renta de aguardiente. Para el siglo XX, no hay un balance, pero sí algunas investigaciones centradas en la historia de la industria en Colombia, es el caso del sociólogo Mayor (1989), quien elaboró una argumentación alrededor de Bavaria como el gran hito industrial en Colombia desde el siglo XIX hasta finales de los 60 del siglo anterior. Sin embargo, las fábricas de licores departamentales son excluidas totalmente de su investigación.

Por otro lado, el compendio de 35 artículos en dos tomos de Dávila (2003) titulado "Empresas y empresarios en la historia de Colombia, siglos XIX y XX", se caracterizan por las vicisitudes de un autor a otro y por su enfoque hacia un público no solo universitario, sino también empresarial. En lo que respecta al compendio no aparece ninguna relación con la industria de licores no sólo en Santander, sino en toda Colombia. Otras investigaciones, por ejemplo la de Sáenz (2002) centrado no solo en el hecho histórico de la creación de Ecopetrol, sino en todos los actores, sus intereses y contextos, permitieron una nueva mirada a este tipo de procesos.

La historiografía sobre empresas o empresarios se ha enfocado en departamentos como Antioquia, Atlántico, Cundinamarca y el Valle del Cauca, cuyos objetos de estudio han sido la banca, el comercio, la minería y el café. Fue la investigación de Luisa Giraldo sobre el antiguo Caldas, quien mencionó algunas páginas sobre la Empresa Licorera de Caldas; respecto a los demás departamentos son inexistentes las investigaciones.

Finalmente, la historiografía colombiana palidece de estudios sobre el desarrollo industrial de las empresas licoreras en todo el país, empresas que albergan la historia del monopolio de la producción de licores destilados en Colombia y todas las vicisitudes tanto en su producción como en el consumo de sus bebidas en cada uno de los departamentos. Situación muy diferente en otros países latinoamericanos como México, Argentina y Brasil, que basta con sólo un vistazo en el internet y el pulque, el tequila, el vino y la cachaza hacen su aparición.

Bajo este panorama se busca rastrear en fuentes y bibliografía, los antecedentes y el origen de la Empresa Licorera de Santander (ELS), con algunas características a manera introductoria para investigaciones a futuro. Cuando se habla de antecedentes, necesariamente se remite a la Real Fábrica de 
Aguardiente del Socorro y respecto al origen, se tomó como referencia desde la legislación de la lucha antialcohólica en 1923, con la aparición de la Fábrica de licores de Floridablanca hasta su puesta en marcha como empresa del departamento, básicamente se interpretó como una breve historia de la Empresa Licorera de Santander (ELS).

\section{Antecedentes de la Empresa Licorera de Santander (ELS)}

El estanco de aguardiente durante el periodo de la Colonia en los territorios que hoy se conocen como Colombia, era básicamente un monopolio para la producción y comercialización de la bebida alcohólica a base de caña de azúcar, como institución española estuvo precedida por órdenes y reales cedulas que prohibieron el consumo de aguardiente entre los años 1693-1697. Según Mora (1988) su creación tuvo idas y venidas desde la real cedula del 23 de septiembre de 1700 hasta su confirmación final en 1736, el establecimiento del estanco generó voces de protesta en contra de la intervención estatal en una actividad que había sido de libre producción, de igual forma, los mercaderes de aguardientes y vinos españoles señalaban la disminución de sus ganancias; en medio de la discusión, las censuras de excomunión de la iglesia agregaba el componente moral. La contraparte oficialista argumentaba los beneficios para el fisco y la solución a la embriaguez de indios, negros, mulatos y mestizos, a través de los altos costos, se pensaba la disminución del consumo.

En sus primeros años el estanco funcionó bajo un sistema de arriendo, consistía en el nombramiento de una persona a través de remate público para la administración de la producción y venta de aguardiente. A cambio, esta persona pagaba al Estado colonial una suma calculada según la región 0 provincia. Durante estos primeros años hubo una incertidumbre respecto al futuro del estanco de aguardiente, que finalmente fue disipada por la real cedula del 14 de septiembre de 1736, su ejecutor fue el presidente Don Sebastián Eslava. (Hernández de Alba, 1990). Con la ratificación del estanco de aguardiente, el sistema de arrendamiento era la opción para la administración de la renta, pero ante los pobres resultados, se implantó el sistema de asiento.
Los asentistas eran intermediarios entre los productores de miel y el estado, ellos pagaban un impuesto por botija producida y su nombramiento era igual al anterior sistema de arriendo, pero con la firma de capitulaciones o compromisos adquiridos. Con este sistema el Estado creó un cuerpo burocrático para llevar la contabilidad del producto, de la productividad y de la renta, además se inició una expansión del control fiscal por la mayoría del territorio (Mora, 1988). Los inconvenientes entre los productores de miel y el asentista, se propiciaron porque este último era quien tenía el derecho a la destilación y la selección de sus proveedores de miel. Por otro lado, el asentista defraudaba al Estado, cuando no declaraba el valor real de las botijas producidas. Este sistema buscó un control de la producción pero descuido la circulación o la venta de aguardiente situación observada por los funcionarios reales.

Desde 1760 bajo el gobierno del Virrey Don José de Solís se estableció paulatinamente un nuevo sistema para el estanco de Aguardiente. Ese sistema fue llamado administración directa, como su nombre lo indica, no hay intermediarios 0 asentistas, el estado colonial con sus funcionarios e instalaciones, elaboró y comercializó el aguardiente de caña. Según Mora (1988) el sistema fue generalizado bajo las instrucciones del Virrey Flores en 1776 y las del visitador José Gutiérrez de Piñeres en 1778, quien revalidó la conveniencia del sistema por arrendamiento en lugares de difícil provecho para la Real Hacienda.

Con el aumento de intervención del estado colonial en la implantación del monopolio o estanco de aguardiente, el proceso de producción se alteraba, es decir, los trapiches y las haciendas constituyeron la unidad productora por excelencia en la fabricación de aguardiente ilegal y legal en el siglo XVII y las primeras décadas del siglo XVIII. Entre 1749-1760, la tendencia ubicó a la vivienda como sitio de destilación, previa autorización del asentista. Para González (2002) a partir de 1760 con la instauración del sistema de administración directa y las reales fábricas, los espacios se especializaron según las distintas funciones administrativas, de producción, de almacenamiento y de venta del producto, incluyendo los espacios para la vivienda del administrador (funcionario del estado) como único referente del 
anterior espacio productivo. A pesar que la hacienda productora fue traslada por la real fábrica, siguió como proveedor de miel.

La instalación de reales fábricas de aguardiente en el siglo XVIII estaba supeditada a unos requerimientos de abasto de materias primas (la miel, el agua, el anís y la leña), de comunicación, de un mercado de consumidores y la importancia económica de la jurisdicción de la administración. Las primeras fábricas fueron las de Santa Fe, Honda, Mompóx, Cartagena, Cali, Popayán y Santa Marta. Posteriormente se adicionaron las de Corozal y Villa de Leiva. Finalmente en el afán expansionista del estanco se crearon las de Socorro, Medellín, Valledupar, Ocaña y Neiva. Para González (2002) la construcción de 14 reales fábricas de aguardiente en todo el virreinato, fue muestra de la agresividad fiscal pero también de la expresión arquitectónica industrial del siglo XVIII, en donde predominaron dos tipos: el de Vivienda y el Basilical. Para el caso de la Real Fábrica del Socorro estuvo en el primer tipo caracterizado por la refuncionalización de una vivienda a un uso industrial.

La referencia más antigua de una fábrica de licores en los territorios que comprenden en la actualidad el departamento de Santander en Colombia fue en la Villa de Nuestra Señora del Socorro y data aproximadamente de 1785. Esta villa se ubicaba en la provincia de Tunja, perteneciente al Virreinato de la Nueva Granada y dominio de la monarquía Española. La orden del Rey Borbón hacia el virreinato, inmediatamente de la aplicación del sistema de administración directa sobre los aguardientes fue construcción de Reales Fábricas de guardiente por todo el territorio, incluyendo la pequeña villa.

La Real Fábrica de Aguardiente del Socorro fue construida en el predio de Don Salvador Plata, una de las personas más poderosas no solo de la villa, sino del virreinato, este predio fue conocido posteriormente como la Casa del Virrey, porque allí se hospedó el arzobispo Caballero y Góngora en 1781. Don Salvador Plata fue nombrado Administrador de Aguardientes y fue el primero en destilar aguardiente en la real fábrica en abril de 1791. Años después su yerno, Miguel Tadeo Gómez fue nombrado como administrador de aguardientes, lideró la instalación de dos nuevos alambiques y también la ampliación de la Real Fábrica con el predio contiguo en 1808 (González, 2002).

Según Mora (1983) el periodo de expansión y mayor crecimiento de la renta estancada del aguardiente se ubicó entre 1760 y 1790 , convirtiéndose en una de las rentas pingües de la Real Hacienda. Esto se debió al inicio de la administración directa del estanco, la creación de reales fábricas y las instrucciones del visitador Gutiérrez de Piñeres en 1778, que optimizaron el aparato fiscal del virreinato. En este periodo el objetivo era el control de la producción y comercio; y el rendimiento de todas las regiones del país, estrategia eficaz en el incremento de la renta.

En la primera década del siglo XIX según cifras de Groot (1909) el estanco de aguardiente perdió protagonismo frente a otro estanco, el de tabaco. En la transición de un gobierno monárquico a uno republicano se pretendió desestancar el aguardiente y se dio vía libre para su producción y comercialización, según la ley del 4 de 0ctubre de 1821. Sin embargo, la improductividad de la renta de aguardiente y la presión de las altas esferas, obligó a Simón Bolívar el 14 de marzo de 1828 a estancar nuevamente el aguardiente (Martínez, 2008). Así, retomando el sistema de arrendamiento de la segunda mitad del siglo XVIII propuesto por la monarquía española.

Durante el periodo federal, a pesar del radicalismo ideológico en estas tierras, el estado Soberano de Santander mantuvo el sistema de arrendamiento, a través de remate público. Los rematadores no podían ser empleados civiles o militares del gobierno, eran personajes 0 sociedades adineradas e influyentes que destilaban y comercializaban el aguardiente en ciertos distritos por un periodo de uno a tres años y con dos fiadores según el valor del remate. Cada rematador otorgaba licencias para la producción, transporte y comercialización de aguardiente dentro del territorio y tiempo comprendido en su remate. Finalmente, el rematador tenía la facultad de supervisión de alambiques y tiendas para evitar el fraude (Código de leyes i decretos, 1866).

Fue la Ley 14 de 1865 la responsable de la renta de aguardiente tanto en el sistema de arrendamiento como en la administración directa. Este último se presentó en casos excepcionales, cuando no había 
rematadores en uno o varios distritos, el Presidente del Estado Soberano de Santander, a través de sus funcionarios, los colectores de Hacienda o comisionados de distrito, otorgaban licencias para la producción de aguardiente, transporte y venta. Estas licencias acarreaban una responsabilidad fiscal, ya sea por la producción de licor, la introducción para la venta de un distrito a otro y la venta al por menor. Finalmente los comandantes de resguardo sirvieron como funcionarios de control de fraude sobre la renta. "El sistema de administración para la segunda mitad del XIX fue de carácter excepcional como ocurrió en 1879 en los distritos de Charalá, Coromoro, Confines, Encino y Ocamonte" (Páez, 1998, p. 47).

Durante el primer siglo de vida republicana, el monopolio no fue desmontado definitivamente tanto en el sistema político centralista como en el federalista. De igual forma, en el trascurso del siglo XIX y las dos primeras décadas del XX se mantuvo el tipo de administración en arrendamiento, situación comparada con la experiencia de la monarquía española del siglo XVIII, bastaron aproximadamente tres décadas para cambiar el tipo de administración en arriendo por una directa, generando altas ganancias a la Hacienda Real.

\section{Origen de la Empresa Licorera de Santander (ELS)}

Los orígenes de la Empresa Licorera de Santander se hallaron en la legislación de la lucha antialcohólica formulada en la segunda década del siglo XX. Si bien, la aparición como empresa se da a mitad de siglo, los cambios ocurridos décadas atrás facilitaron su creación y posterior consolidación en el departamento de Santander.

Durante el siglo XIX y las dos primeras décadas del siglo XX se consolidó el monopolio de licores por parte del estado, este monopolio fue a través de un sistema de arriendo, en donde el estado no intervenía en la producción, distribución y consumo. Fue con la legislación de la lucha antialcohólica entre 1923-1928 que el sistema cambió, de uno en arriendo a una administración directa de todo el proceso de elaboración de licores destilados como el aguardiente. Este cambió es reconocido como el origen remoto de la Empresa Licorera de Santander, porque este tipo de administración requería fábricas y expendios oficiales como ocurrió a finales del siglo XVIII, bajo la corona española (Sierra, 2011).

El Dr Emilio Pradilla, como Gobernador del departamento, creó la estructura burocrática de la renta de Licores Destilados cuya cabeza era el Administrador General, seguido por los administradores de las fábricas oficiales de licores que en sus inicios contó con 5 establecimientos, dispersados por todo el territorio en municipios como: Florida, Málaga, Mogotes, Socorro y Vélez (Departamento de Santander, 1923). Bajo los administradores seguía una serie de cargos que cumplían las nuevas necesidades de la renta que se alteraba con el cambio de administración propuesta desde la legislación de la lucha antialcohólica.

Con el inicio de las 5 fábricas de licores en el departamento, los requerimientos económicos no dieron espera, en un informe presentado por el Gobernador del departamento entre septiembre de 1923 a noviembre de 1924 se invirtieron alrededor de 77.000 pesos colombianos tanto en la compra de aparatos, mobiliario, compra de rones y otros licores (Departamento de Santander, 1924). A pesar de las cifras, para Sierra (2011) esta inversión fue rápidamente solventada por los dineros ingresados en la renta de Licores Destilados registrados en los presupuestos del departamento de Santander. Al igual que su símil del siglo XVIII, las pequeñas y recientes fábricas de licores bajo el sistema de administración directa fueron todo un éxito fiscal para el tesoro departamental.

Ante el notorio éxito de la renta de Licores Destilados con sus fábricas, las mejoras no se hicieron esperar. Para la fábrica de Floridablanca la optimización de sus instalaciones y la actualización de los aparatos para la producción de licores ya no solo el aguardiente, sino el ron y vinos de frutas, permitió una mayor administración, diversificación y control en la producción al interior de la fábrica (Departamento de Santander, 1925).

Para la producción de Ron y otras bebidas, la gobernación firmó un contrato con Samuel Martínez, experto en la elaboración de bebidas como: Ron Matusalén, Ron Común, Ron Blanco, Ginebra, Bay- 
Rum y Bay Kool. Dentro del contrato figuraban beneficios a futuro para la fábrica como:

Noveno: Se hace constar que el Departamento queda en libertad de confeccionar en sus fábricas o destilerías toda clase de licores, aun de los mismos nombres y calidades de los que produce el Contratista, sin la intervención de este, pero es sobreentendido que no los dará al expendio con etiquetas iguales ni con los nombres especiales que usa para sus productos el Contratista, ni bajo el nombre de este. (Departamento de Santander, 1927, p. 466.)

En un informe presentado por Carlos Ardila, secretario de Hacienda al señor Gobernador del departamento de Santander en 1926, acerca de las 4 fábricas ${ }^{1}$ oficiales del departamento, cada una de las fábricas correspondía a zonas por ejemplo: la de Bucaramanga- Piedecuesta estaba con la fábrica de Florida, la de Málaga-San Andrés con la fábrica de Málaga, las dos zonas la de Sangil-Charalá y Vélez con "La Capilla", finalmente la zona de Socorro con la "la Armenia". La fábrica más importante por tamaño, por producción (ver tabla 1) y la única propietaria del terreno en donde se ubicaba, era la de Florida. Respecto al número de estancos, (almacén y expendio oficial de los productos de la renta de licores) de los 79 existentes en el departamento, 20 correspondieron a la zona Bucaramanga-Piedecuesta (Ardila, 1927, p 219). Es decir, fue la más importante para la Gerencia de Rentas, situación que se mantuvo hasta la creación de la empresa Licorera de Santander.

A medida que se consolidaba la fábrica de licores de Floridablanca, la diversificación de sus productos se hacía una necesidad, la celebración de contratos para la elaboración de nuevos productos como whisky, brandy, curazao, cremas, ginebra, Bay-rum, lociones y licores de perfumería, fue el contrato con Ralph Tourne, que comprendía no sólo lo anterior, sino una supervisión en su producto base el aguardiente. (Departamento de Santander, 1928). Al interior del contrato se gestó una necesidad por

1. La fábrica de Mogotes fue suprimida en 1924, y sus utensilios fueron enviados a la del socorro y los licores con el asentista de San Gil para facilitar la distribución en los estancos. Esta supresión fue según la Gaceta de Santander, Decreto \#225 de 1924. mejorar la calidad de los productos, ante constantes señalamientos respecto a denuncias en la prensa de Bucaramanga por el uso de sustancias nocivas (Vanguardia Liberal, 1928).

ITabla 1.

\section{Producción de licores y alcohol puro de las fábricas oficiales del departamento en 1926}

\begin{tabular}{|l|c|c|c|}
\hline Fabrica & $\begin{array}{c}\text { Botellas de } \\
\text { Aguardiente }\end{array}$ & $\begin{array}{c}\text { Alcohol } \\
\text { Puro }\end{array}$ & $\begin{array}{c}\text { Licores } \\
\text { Varios }\end{array}$ \\
\hline Florida & 292.213 & 29.535 & 9.200 \\
\hline Málaga & 76.380 & 1.655 & 1.740 \\
\hline La Armenia & 62.462 & & 2.744 \\
\hline La Capilla & 36.492 & 1.432 & 1.753 \\
\hline Totales & 467.547 & 32.622 & 15.437 \\
\hline
\end{tabular}

Fuente: Elaboración propia basada en Ardila, C. (1927), Informe del secretario de Hacienda al señor gobernador, relativo a las labores de 1926. Tomo II (Anexos). Bucaramanga: Tip Mercantil-Nigrinis Hnas.

La fábrica de Floridablanca, conocida también como el zaque, para los treintas ofrecía una gran cantidad de productos, con excepción de whisky y curazao. De manera especial se inició la producción de "Elixir Santander" "Anís Sevillano" y "Anisado Pichón", acompañando a los tradicionales aguardientes "el Común" y "Superior". Esta producción local era la competencia para las bebidas extranjeras que ingresaban al departamento y consumidas en los sitios más exclusivos.

La indiscutible posición de los aguardientes durante los años treinta (Ver tabla 2) expone su relevancia, seguido por los rones, vinos y finalmente los anisados, cremas y ginebra. El consumo aumentó considerablemente con el paso del tiempo, impulsado no solamente por el éxito de dichos licores, sino también por la intervención del gobierno, con medidas restrictivas respecto a los consumidores tradicionales como la chicha y el guarapo, a través de la aplicación de la legislación de la lucha antialcohólica propuesta desde 1923. 
Tabla 2.

Consumo de botellas de licor de 720 gramos de fabricación oficial de 1931-1938

\begin{tabular}{|l|c|c|c|c|c|c|c|c|}
\hline $\begin{array}{l}\text { Botellas de } \\
\text { licor de 720 } \\
\text { gramos }\end{array}$ & 1931 & 1932 & 1933 & 1934 & 1935 & 1936 & 1937 & 1938 \\
\hline $\begin{array}{l}\text { Aguardiente } \\
\text { y mistelas }\end{array}$ & 290.257 & 260.803 & 322.457 & 435.676 & 415.772 & 461.769 & 561.844 & 641.603 \\
\hline \begin{tabular}{l} 
Rones \\
\hline $\begin{array}{l}\text { Anisados, cremas } \\
\text { y ginebra }\end{array}$
\end{tabular} & 38.153 & 61.562 & 76.569 & 124.094 & 207.723 & 245.577 & 265.414 & 255.763 \\
\hline $\begin{array}{l}\text { Vinos de } \\
\text { Santander }\end{array}$ & 2.709 & 15.288 & 11.984 & 21.234 & 21.818 & 34.125 & 37.633 & 45.453 \\
\hline TOTALES & 351.206 & 353.169 & 442.272 & 654.846 & 737.881 & 858.424 & 979.366 & 1.079 .580 \\
\hline
\end{tabular}

Fuente: Contraloría Departamental. (1939). Anuario Estadístico de Santander 1938. Bucaramanga: Imprenta del Departamento, p. 99.

La restricción en la producción artesanal de fermentados como la chicha y el guarapo, y la desaparición de su renta en 1937, le permitió al gobernador Alfredo Cadena, a través de la Administración General de Rentas, la creación de una política de stock de licores, para contrarrestar la ausencia de estas bebidas tradicionales, esta política consistió en el aumento de la producción de licores y una medida de añejamiento, esta medida nunca había sido aplicada en la historia de fabricación de licores en Santander; en cifras se mencionó, la existencia de licores a diciembre de 1935 fue de 557.464 botellas frente a 957.728 para 1937 (Departamento de Santander, 1938). Con esta medida se resolvía dos situaciones: el mejoramiento de la calidad en los licores por el añejamiento y se esperaba cubrir la demanda de los consumidores de bebidas artesanales como chicha y guarapo, que habían sido prohibidas en el departamento de Santander desde 1937.

Durante la legislación de la lucha antialcohólica en 1923-1928, se presentó el tránsito de una administración de arriendo a una directa, situación similar presentada en las últimas décadas del siglo XVIII, en ambos casos, se presentaron incrementos en los ingresos con el cambio de administración, las razones estribaron en un control activo sobre la producción y comercialización de los destilados y la eliminación de intermediarios en los anteriores procesos. Para el siglo XX, según "los presupuestos departamentales, en el periodo fiscal del 1 de julio de 1922 al 30 de junio de 1923 la renta de Licores Destilados recaudó 206.380 pesos colombianos" (Departamento de Santander, 1922). Luego de aplicada la nueva administración, la cantidad fue 350.000 pesos colombianos, para los siguientes periodos, la renta de Licores Destilados nunca descendió, todo lo contrario, tuvo un ascenso paulatinamente (Sierra, 2009). Es decir, tanto el estanco de aguardiente del siglo XVIII como el monopolio de Licores Destilados del siglo XX, bajo la administración directa generaron ganancias ya sea tanto al Virreinato como al tesoro departamental.

Las economías latinoamericanas fueron sacudidas por distintas crisis durante el periodo de las guerras mundiales y la gran depresión de 1929, situación que en la década del treinta, se presentará un punto crítico de ruptura respecto al modelo primarioexportador (Tavares, 1979). De manera similar en Colombia, la historia de la industria en esas décadas oscila con esos dos momentos de estancamiento en los comienzos del treinta por la crisis mundial y en los cuarenta por la segunda guerra mundial. Siendo la posguerra la oportunidad de la implantación de la industrialización sustitución de importaciones como 
la apuesta política y económica de los gobiernos latinoamericanos y colombiano (Garay, 1998).

En la producción industrial en Colombia para 1941 (según la Estadística Nacional), de las 1.569 fábricas se vendieron 198.978.385 pesos colombianos, la lista de los sectores más productivos estuvo liderada por: hilados y tejidos con $\$ 50.028 .680$, cigarros y cigarrillos $\$ 27.833 .837$, cervezas $\$ 20.323 .519$ y licores destilados $\$ 14.970 .207$ (Vanguardia Liberal, 1943). Los datos estadísticos que revalidan la importancia del sector de los licores destilados a nivel nacional en términos de producción industrial y a diferencia del sector privado de las cervezas, la mayor parte de las ganancias entraban a los tesoros departamentales. Ante ese panorama, la historiografía local y nacional brilla por la ausencia de estudios que determinen el protagonismo de la industria de licores en periodos de crisis como de auge de la economía nacional y en los presupuestos departamentales.

En la década del cuarenta se consolidaba la Fábrica de Licores de Floridablanca por su producción y variedad de licores para el mercado departamental. En otras ciudades como Manizales paralelamente a su producto insignia el Ron Viejo de Caldas, también se invertía en nuevos proyectos para la producción de otros licores como whisky, e incluso la cerveza, dependientes de la Industria Licorera de Caldas creada en 1943 (Giraldo, 2001).

En Santander, el aguardiente Superior fue ampliamente el producto de mayor acogida en el departamento, seguido del aguardiente Común, rones, cremas nacionales y ginebra (Ver tabla 3). Sin embargo, las cifras no ocultan una problemática al interior de las fábricas oficiales, incluyendo la de Floridablanca. La administración General de Rentas de Santander estaba encargada de la renta de licores destilados y de sus fábricas; dentro de los problemas más visibles estuvo la falta de dinero en efectivo para la realización de operaciones comerciales de contado, situación que dificultaba su administración, la contabilidad y la labor de la contraloría misma, disputas bipartidistas y hasta robos (Vanguardia Liberal, 1949). Sumado a este, los problemas por insumos como botellas, anís, y
Carol, quien la denominó como la Joya de los Santandereanos, por su caldera tubular último mode-

|Tabla 3.

\section{Consumo de botellas de licor de 720 gramos de fabricación oficial en Santander 1945-1947}

\begin{tabular}{|l|c|c|c|}
\hline $\begin{array}{l}\text { Botellas de licor de } \\
\mathbf{7 2 0} \text { gramos }\end{array}$ & 1945 & 1946 & 1947 \\
\hline Aguardiente Superior & 433.108 & 518.835 & 464.750 \\
\hline Aguardiente Común & 269.200 & 293.620 & 172.508 \\
\hline Mistelas & 13.711 & 13.578 & 9.764 \\
\hline Ron Blanco & 139.058 & 181.007 & 176.578 \\
\hline Ron Común & 55.729 & 67.194 & 62.304 \\
\hline Ron Málaga & 4.188 & 195 & 27 \\
\hline Ron Viejo & 46.920 & 67.358 & 60.614 \\
\hline Ron San Cristóbal & 98.516 & 95.016 & 51.142 \\
\hline Ginebra & 5.880 & 9.769 & 5.210 \\
\hline Cremas Nacionales & 26.715 & 15.041 & 16.591 \\
\hline Anisados Finos & 74.783 & 81.181 & 68.886 \\
\hline
\end{tabular}

Fuente: Contraloría Departamental. (1949). Anuario Estadístico de Santander 1947. Dirección Departamental de Estadística. Bucaramanga: Imprenta del Departamento, p. 65.

algunas frutas para la elaboración de vinos, eran evidentes con avisos en la prensa local.

La administración directa de la Renta de Licores Destilados y las fábricas oficiales fueron el origen de la Empresa Licorera de Santander. El monopolio para la fabricación y comercialización de los licores destilados, aseguraba el éxito de esta actividad económica gubernamental. La fábrica de licores de Floridablanca y su moderna destilería fueron la columna vertebral de lo que se llamó la Empresa Licorera de Santander en 1948.

"La fábrica de licores de Floridablanca, una de las más modernas instalaciones de América" tituló un artículo del Boletín de la Contraloría en 1948, en términos generales era una traducción del informe elaborado por el Técnico Ingeniero J. Contijoch 
lo de la Casa Savalle de Paris, su Digestor o mezclador con paletas helicoidales que transforman la panela en un melaza uniforme, las cubas-madres de fermentación, los modernísimos "lebbens", criadores de levaduras, los "lepages", aparatos de destilación que extraen tres tipos de alcohol de la reconocida Casa de Lepage, Urbain \& Cie., y por último la planta de electricidad, asegura el flujo constante y económico de la energía (Contraloría Departamental, 1948). Así como Bogotá tenía las instalaciones de Bavaria como símbolo de la industria nacional, Floridablanca tenía La Fábrica de Licores como símbolo de la industria Santandereana.

En 1948 La Asamblea Departamental a través de la ordenanza \# 70 creaba la Empresa Licorera de Santander como una organización exclusivamente industrial y comercial. Esta empresa constaba de completa autonomía en el manejo de sus fondos, inversiones y transacciones comerciales propias de la producción, distribución, importación, exportación de licores monopolizados (Departamento de Santander, 1949a).

Con la creación de la Empresa Licorera de Santander como entidad independiente en el manejo de sus utilidades, alteró algunas funciones a la Administración General de Rentas, fue eliminada y convertida en una sección técnica de impuestos y rentas del departamento adscrita a la secretaría de Hacienda, con tres secciones: 1 . Negocios generales; 2 . Recaudación de impuestos y rentas; y 3 . Vigilancia y resguardo de las rentas (Gómez, 1951). La empresa también suplantó la Administración General de Rentas en lo referente al recaudo de los dineros producto del monopolio de licores extranjeros autorizado desde 1947. De este modo, la Empresa Licorera de Santander tuvo un impacto no sólo industrial sino también en lo relacionado a la estructura fiscal del departamento.

El gobernador Valentín González Rangel ratificó por decreto \#711 de 1948 la creación de la Empresa Licorera de Santander; sin embargo, con la llegada del nuevo gobernador la situación se revirtió, Hernando Sorzano González aplazó su ratificación y aplicación, basado en el artículo 192 de la Constitución Nacional y el artículo 127 del código de Régimen Político y Municipal. Argumentando múltiples circunstancias de carácter legal y técnico que impiden proceder con tanta premura al inicio de labores de la empresa (Departamento de Santander, 1949b). En el centro de la disputa estaba la distribución de las ganancias de la empresa en el departamento.

El panorama de las fábricas de Licores en todo el país en 1950, evidenció que los departamentos del Chocó, Magdalena y Tolima, tenían fabricas obsoletas, por otro lado Antioquia, Atlántico, Bolívar, Boyacá, Cundinamarca, Norte de Santander y Valle del Cauca, iniciaron procesos de actualización, restando las fábricas de los departamentos de Caldas y Santander como las mejores del país (Gómez, 1951). La modernización de la fábrica como la autonomía en el uso de recursos eran factores indispensables para el mejoramiento de los productos y el éxito de la Empresa Licorera de Santander.

Sólo hasta 1951, se ratificó la creación de la Empresa Licorera de Santander bajo el decreto \#217. Este decreto señaló el carácter netamente industrial y comercial de la empresa, con una Tesorería propia e independiente de la Tesorería General del Departamento. Su Gerente General tendrá como asesor a la Junta Técnica-Consultiva (Departamento de Santander, 1951). También se resolvió el punto neurálgico respecto a la distribución de las ganancias de la venta de productos elaborados por la empresa y consumidos en el departamento: el $70 \%$ para la Tesorería Departamental y el $30 \%$ restante para la Empresa Licorera de Santander. Por otro lado, la importación y posterior venta de licores, vinos y cigarrillos extranjeros le corresponde el $5 \%$ para la empresa y el $95 \%$ a la Tesorería Departamental. Adicionalmente, la utilidad en ventas de productos exportados a otros departamentos del monopolio oficial, más los alcoholes, lociones y perfumes se divide en partes iguales entre el departamento y la empresa (Departamento de Santander, 1951). Esta distribución difiere de la planteada en la ordenanza \#70 de 1948, en donde el departamento obtenía el $45 \%$, los municipios el $40 \%$ y solo el $15 \%$ para la empresa, distribución que limitaba la posibilidad de crecimiento de la empresa y una disminución considerable de los dineros del Tesoro Departamental. 
Tras una serie de problemas de orden legal en su origen y ratificación por parte del ejecutivo departamental, el 20 de Diciembre de 1952 fue inaugurada la nueva destilería de la Empresa Licorera de Santander, cuyo origen francés y según un artículo en la prensa local producirá los mejores licores no solo de Colombia, sino de Sur América (Vanguardia liberal, 1952).

Los primeros años de la Empresa licorera de Santander estuvieron marcados por la incertidumbre de su creación y seguidamente, tras la finalización de las obras de modernización, una eclosión industrial que al pasar de las décadas terminará apagándose y desapareciendo tanto física como mentalmente para las nuevas generaciones, que reconocen con facilidad aguardientes de fábricas de otros departamentos, pero ignoran el sabor que tuvo en algún momento el aguardiente de los santandereanos.

\section{Conclusión}

El título del artículo esboza dos momentos concretos: 1. Los antecedentes de la Empresa Licorera de Santander y 2. Sus orígenes.

Respecto a los antecedentes más remotos en los territorios de la Empresa Licorera de Santander, se hallaron en el siglo XVIII, bajo la corona española y en el virreinato de la Nueva Granada, durante la segunda mitad de siglo se transitó de una administración en arriendo a una directa, situación que permitió la creación de la Real Fábrica de Aguardiente del Socorro. Estos cambios en la estructura fiscal, en los albores del proceso independentista representaron los ingresos más altos para el tesoro del virreinato.

El origen de la Empresa Licorera de Santander surgió como se mencionó anteriormente, a partir de un proceso de monopolización por parte del estado colombiano, iniciado desde la legislación de la lucha antialcohólica en 1923 hasta la ratificación en 1951 como empresa industrial y comercial, con tesorería independiente respecto a la departamental. La legislación de 1923 se concentró en el cambio de una administración en arriendo a una directa, situación que nuevamente permitió la creación de empresas licoreras en todo el departamento, garantizando un incremento en el tesoro del departamento de Santander. Antes de la ratificación, se presentó un proceso de consolidación de la Fábrica de licores de Floridablanca frente a las demás, siendo la base para la creación de la Empresa Licorera de Santander (ELS).

La comparación de ambas experiencias industriales determinó que la implementación del sistema de administración directa, que básicamente era un monopolio en la elaboración, distribución y consumo de licores destilados, garantizó el éxito fiscal 0 monetario de la renta en ambos casos, a pesar de la temporalidad y el contexto.

La historia de los licores en la Nueva Granada y posteriormente en Colombia, no ha sido abordada de manera completa por la historiografía, hay muchos vacíos que no permiten analizar la complejidad del consumo de licores y sus distintas relaciones con el estado, la sociedad, la economía e incluso con procesos de identidad en torno a una bebida. A manera de ejemplo, los estudios de las empresas licoreras alrededor del país son todo un misterio, incluso en la historia industrial de las décadas del cincuenta y sesenta del siglo XX, son oscurecidos por los trabajos existentes sobre la cervecería Bavaria. La información de estas empresas licoreras aportan en la resolución de problemáticas respecto a la situación económica de Colombia a mitad del siglo $X X$, si era de un estancamiento o consolidación de un capitalismo (León, 2004).

\section{Referencias BibliográFicas}

Ardila, C. (1927), Informe del secretario de Hacienda al señor gobernador, relativo a las labores de 1926 . Tomo II (Anexos). Bucaramanga: Tip Mercantil-Nigrinis Hnas.

Código de Leyes i Decretos (1866). Espedidos por la Asamblea de Santander en sus sesiones de 1865. Pamplona: Imprenta de Zapata Hermanos.

Contraloría Departamental. (1939). Anuario Estadístico de Santander 1938. Bucaramanga: Imprenta del Departamento. Contraloría Departamental (1948). Boletín de la Contraloría Departamental, Año XIII, \#47, boletín mensual de septiembre. Bucaramanga: Imprenta del Departamento.

Contraloría Departamental. (1949). Anuario Estadístico de Santander 1947. Dirección Departamental de Estadística. Bucaramanga: Imprenta del Departamento. 
Dávila, C. (Ed.). (2003). Empresas y empresarios en la historia de Colombia, siglos XIX y XX. Una colección de estudios recientes, Tomo I. Bogotá: Editorial Norma.

Departamento de Santander. (1922). Gaceta de Santander. Junio 4 de 1922, \# 5009. Decreto 109 de 1922, p 160. Bucaramanga: Imprenta del departamento.

Departamento de Santander. (1923). Gaceta de Santander. Septiembre 4 de 1923, \#5056. Decreto 130 de 1923, p. 213. Bucaramanga: Imprenta del departamento.

Departamento de Santander. (1924). Gaceta de Santander. Diciembre 27 de 1924, \#5135. Discurso del Gobernador entrante, p 450. Bucaramanga: Imprenta del Departamento.

Departamento de Santander. (1925). Gaceta de Santander. Diciembre 14 de 1925, \#5194. Decreto 148 de 1925, p. 480. Bucaramanga: Imprenta del departamento.

Departamento de Santander. (1927). Gaceta de Santander. Diciembre 13 de 1927\#5314. Contrato sobre suministro y producción de licores p. 466. Bucaramanga: Imprenta del departamento.

Departamento de Santander. (1928). Gaceta de Santander. Noviembre 23 de 1928 \#5373. Contrato sobre prestación de servicios técnicos para la fabricación de licores, p. 522. Bucaramanga: Imprenta del departamento.

Departamento de Santander. (1938). Gaceta de Santander. Junio 25 de 1938, \#5864. El gobernador y el debate sobre la cuestión fiscal, p. 283. Bucaramanga: Imprenta del departamento.

Departamento de Santander. (1949a). Gaceta de Santander. Febrero 5 de 1949 \#6296. Ordenanza \#70 de 1948, p 51. Bucaramanga: Imprenta del departamento.

Departamento de Santander. (1949b). Gaceta de Santander. Junio 4 de 1949, \#6313. Decreto 711 de 1949, p. 225. Bucaramanga: Imprenta del departamento.

Departamento de Santander. (1951) Gaceta de Santander. Abril 14 de 1951 \#6357. Decreto218 de 1951 p. 127. Bucaramanga: Imprenta del departamento.

Es un peligro para la salud la impureza de los alcoholes que en Santander se fabrican (1928, 13 de enero). Vanguardia Liberal, p. 1.

Garay, L. (Ed.). (1998). Colombia: Estructura industrial e internacionalización 1967-1996. (pp.19-64). Tomo I. Bogotá: Departamento de Planeación Nacional.

Giraldo, L. (2001). Modernización e industrialización en el Antiguo Caldas 1900-1970. Manizales: Universidad de Caldas, Centro Editorial.

Gómez, L. (1951). UN AÑO DE GOBIERNO 1950-1951. Informe de las labores desarrolladas en los departamentos y territorios nacionales del 7 de agosto de 1950 al 7 de agosto de 1951. Tomo II. Bogotá: Imprenta Nacional.
González, F. (2002). Reales Fábricas de Aguardiente de Caña en el Nuevo Reino de Granada. Arquitectura industrial siglo XVIII. Bogotá: Centro Editorial Javeriano.

Groot, J. (1909). Asuntos Constitucionales, económicos y fiscales. Bogotá: Moderna.

Hernández de Alba, G. (1990). "El virreinato de la Nueva Granada". En G. Hernández de Alba (Ed) Historia de Colombia, (pp.571-591). Tomo 3. Bogotá: Salvat Editores.

Industrialización de Colombia. (1943, 15 de enero). Vanguardia Liberal, p. 5.

La organización que dictó la Asamblea para la administración de Rentas es la que más conviene a los intereses fiscales. (1949, 06 de Noviembre). Vanguardia Liberal, p. 1 y 4.

León, P. (2004). La literatura sobre la industrialización colombiana: Balance y perspectivas, INNOVAR Revista de Ciencias Administrativas y Sociales. (23), 182-207.

Martínez, A. (2008). La agenda de Colombia 1819-1831. Tomo II. Bucaramanga: Universidad Industrial de Santander.

Mayor, A. (1989). Historia de la Industria colombiana 18861930. En Tirado (Ed) Nueva Historia de Colombia. (pp. 313-332). Vol 5, Bogotá: Planeta

Mora, G. (1988). Aguardiente y conflictos sociales en la Nueva Granada (Siglo XVIII), Bogotá: Universidad Nacional de Colombia.

Mora, G. (1983) La política fiscal del estado colonial y el monopolio de la industria del aguardiente en la Nueva Granada durante el siglo XVIII, Desarrollo y Sociedad, (10), 91-119.

Nueva destilería. (1952, 20 de Diciembre). Vanguardia Liberal, p. 3. Páez, C. (1998). La Administración fiscal de la renta de Aguardiente en el estado soberano de Santander 18571886. Universidad Industrial de Santander. Bucaramanga, Colombia.

Rodríguez, 0. (1995). La historiografía económica colombiana del siglo XIX. En Tovar (Ed) La Historial Final del Milenio, Ensayos de historiografía colombiana y Latinoamericana.(pp.188250). Vol. 1. Bogotá: Universidad Nacional de Colombia.

Sáenz, E. (2002). Colombia años 50, Industriales Política y Democracia. Bogotá: Universidad Nacional.

Sierra, F. (2009). El consumo de licores fermentados en Santander, participación en Rentas y la incidencia en homicidios 1920-1940. Universidad Industrial de Santander, Bucaramanga, Colombia.

Sierra, F. (2011). La legislación de la lucha antialcohólica en Santander 1923-1928. Anuario de Historia Regional y de las Fronteras. (16), 175-194.

Tavares, M. (1979). De la sustitución de importaciones al capitalismo financiero. México: Fondo de Cultura Económica.

Value, N. (2000, 02 de febrero) Licorera de Santander pasa su último trago El Tiempo. 